8 Furman RR, Sharman JP, Coutre SE, et al. Idelalisib and rituximab in relapsed chronic lymphocytic leukemia. N Engl J Med 2014; 370: 997-1007.

9 Gopal AK, Kahl BS, de Vos S, et al. PI3K $\delta$ inhibition by Idelalisib in patients with relapsed indolent lymphoma. N Engl J Med 2014; 370: 1008-1018.

10 Coutre SE, Barrientos JC, Brown JR, et al. Management of adverse events associated with idelalisib treatment: expert panel opinion. Leuk Lymphoma 2015; 1-8.

11 Hadjinicolaou AV, Nisar MK, Parfrey H, et al. Non-infectious pulmonary toxicity of rituximab: a systematic review. Rheumatology 2012; 51: 653-662.

12 Champion L, Stern M, Israël-Biet D, et al. Brief communication: sirolimus-associated pneumonitis: 24 cases in renal transplant recipients. Ann Intern Med 2006; 144: 505-509.

13 Duran I, Siu LL, Oza AM, et al. Characterisation of the lung toxicity of the cell cycle inhibitor temsirolimus. Eur J Cancer 2006; 42: 1875-1880

14 Kaplan B, Qazi Y, Wellen JR. Strategies for the management of adverse events associated with mTOR inhibitors. Transplant Rev 2014; 28: 126-133.

15 Wang WL, Yu LX. Acute respiratory distress attributed to sirolimus in solid organ transplant recipients. Am J Emerg Med 2015; 33: 124.e1-4.

\title{
High-flow nasal oxygen for bronchoalveolar lavage in acute respiratory failure patients
}

\section{To the Editor:}

Fiberoptic bronchoscopy with bronchoalveolar lavage (BAL) holds significant risks of oxygenation deterioration [1]. Among various means to improve oxygenation during BAL, noninvasive positive pressure ventilation (NPPV) has received the greatest attention [2, 3]. However, NPPV is a time-consuming and very demanding technique. High-flow nasal cannula oxygen therapy (HFNC) has emerged as a technique for noninvasive respiratory management of hypoxaemic patients [4]. In patients with acute respiratory failure (ARF), its beneficial effects have been shown in various populations [5], and its effectiveness and superiority over NPPV and conventional oxygenation recently demonstrated [6]. Its use has also been described during bronchoscopy in non-hypoxaemic [7] and in hypoxaemic patients in comparison with NPPV [8]. However, bronchoscopy was performed with an open mouth in both studies, which considerably reduces HFNC efficacy [9]. Thus, we aimed to determine HFNC's effectiveness during nasal bronchoscopy with BAL in patients with ARF along with BAL's feasibility and yield.

We conducted a prospective, observational, multicentre, open study in critically ill patients with ARF. Intensive care unit (ICU) patients from four university hospitals, with ARF and requiring a bronchoscopy with BAL were included in the study. ARF was defined as a respiratory rate $>25$ breaths $\cdot \mathrm{min}^{-1}$ (or $>20$ breaths $\mathrm{min}^{-1}$ if use of accessory respiratory muscles was present) in patients requiring oxygen at $\geqslant 6 \mathrm{~L} \cdot \mathrm{min}^{-1}$ to attain a pulse oximetry measurement of $>92 \%$. Patients were not included if they had contraindications to bronchoscopy with BAL (including respiratory acidosis).

The Ethics Committee of the French Society of Intensive Care (SRLF, Société de Réanimation de Langue Française, Paris, France) approved the study (approval number: 12-374).

HFNC was delivered via a dedicated high-flow delivery system (Optiflow; Fisher \& Paykel, Auckland, New Zealand). Oxygen flow and inspiratory oxygen fraction $\left(\mathrm{FIO}_{2}\right)$ were adjusted to obtain a pulse oximetry measurement $>92 \%$. Bronchoscopy with BAL was performed under local anaesthesia and with careful monitoring. Patients were asked to rate their dyspnoea according to a visual analogue scale, and after each BAL, the operator rated the eventual discomfort related to HFNC. Baseline and subsequent arterial blood gases were collected. Failure of the oxygenation strategy was considered if NPPV or invasive ventilation were needed within $24 \mathrm{~h}$ of the procedure. The study centres followed similar classical intubation criteria [10].

Data were compared according to failure or success of HFNC using the Mann-Whitney U-test, the paired t-test and Fisher's exact test, as appropriate. Changes in physiological measures over time were assessed using one-way ANOVA for repeated measures.

30 ICU patients (median (interquartile range (IQR)) age 54 (46-68) years) were included in the study. Demographics, physiological data and patient outcomes are detailed in table 1 . Within $24 \mathrm{~h}$, five (16.7\%) 
TABLE 1 Demographics, physiological data and patient outcomes

\begin{tabular}{|c|c|c|c|c|}
\hline & Total & Procedure success & Procedure failure & p-value \\
\hline Subjects $n$ & 30 & 25 & 5 & \\
\hline Age years & $54(46-68)$ & $54(46-61)$ & $70(38-76)$ & 0.94 \\
\hline Male sex & $18(60)$ & $15(60)$ & $3(60)$ & 1 \\
\hline SAPSII score & $36(27-43)$ & $36(27-43)$ & $35(24-66)$ & 0.66 \\
\hline ODIN score & $1(1-2)$ & $1(1-2)$ & $1(1-1)$ & 1 \\
\hline Prior HFNC & $18(60)$ & $16(64)$ & $2(40)$ & 0.36 \\
\hline \multicolumn{5}{|l|}{ Baseline physiological data } \\
\hline Respiratory rate breaths $\cdot \min ^{-1}$ & $28(23-34)$ & $28(22-35)$ & 25 (25-32) & 0.37 \\
\hline Heart rate beats $\cdot \min ^{-1}$ & $95(88-113)$ & $95(89-111)$ & $96(71-113)$ & 0.72 \\
\hline Systolic blood pressure $\mathrm{mmHg}$ & $131(119-141)$ & $129(119-141)$ & 135 (116-157) & 0.37 \\
\hline \multicolumn{5}{|l|}{ Baseline arterial blood gases } \\
\hline Administered flow $\mathrm{L} \cdot \mathrm{min}^{-1}$ & $15(9-50)$ & $15(9-60)$ & $9(5-50)$ & \\
\hline $\mathrm{PaO}_{2} / \mathrm{FlO}_{2}$ & $169(145-196)$ & $169(148-200)$ & 135 (113-197) & 0.31 \\
\hline $\mathrm{PaO}_{2} \mathrm{mmHg}$ & 90 (74-123) & 97 (82-140) & $68(57-90)$ & 0.47 \\
\hline $\mathrm{FlO}_{2}$ & $0.59(0.46-0.7)$ & $0.6(0.47-0.85)$ & $0.48(0.36-0.65)$ & 0.82 \\
\hline $\mathrm{PaCO}_{2} \mathrm{mmHg}$ & $36(33-40)$ & $36(31-40)$ & $40(37-51)$ & 0.04 \\
\hline \multicolumn{5}{|l|}{ Arterial blood gases after procedure } \\
\hline $\mathrm{PaO}_{2} / \mathrm{FlO}_{2}$ & $99(98-126)$ & $99(98-113)$ & $122(91-186)$ & 0.12 \\
\hline $\mathrm{PaO}_{2} \mathrm{mmHg}$ & $116(86-165)$ & $122(91-165)$ & $77(67-108)$ & 0.27 \\
\hline $\mathrm{FlO}_{2}$ & $1(0.8-1)$ & $1(0.9-1)$ & $0.8(0.6-1)$ & 0.13 \\
\hline $\mathrm{PaCO}_{2} \mathrm{mmHg}$ & $36(33-40)$ & $36(32-40)$ & $38(36-43)$ & 0.18 \\
\hline Duration of HFNC $h$ & $61(31-95)$ & $64(43-94)$ & $14(6-123)$ & 0.11 \\
\hline Post-bronchoscopy length of hospital stay days & $5(3-9)$ & $5(3-7)$ & $10(5-18)$ & 0.66 \\
\hline Survival & 25 (83.3) & $21(84)$ & $4(80)$ & 1 \\
\hline
\end{tabular}

Data are presented as median (interquartile range) or $\mathrm{n}(\%)$, unless otherwise stated. SAPSII: Simplified Acute Physiology Score II; ODIN: Organ Dysfunctions and/or Infection; HFNC: high-flow nasal cannula oxygen therapy; $\mathrm{PaO}_{2}$ : arterial oxygen tension; $\mathrm{FlO}_{2}$ : inspiratory oxygen fraction; $\mathrm{PaCO}_{2}$ : arterial carbon dioxide tension.

patients experienced failure of the oxygenation strategy, between 2.5 and $14 \mathrm{~h}$ after BAL (four required NPPV, one of whom further required endotracheal intubation (ETI), and one was directly intubated). Reasons were onset of hypercapnia after the procedure (two patients) and worsening hypoxaemia (three patients). There was no significant difference in the patients' baseline characteristics when comparing success and failure.

During bronchoscopy, median (IQR) HFNC flow was 50 (50-60) L-min ${ }^{-1}$ with an $\mathrm{FIO}_{2}$ of 1 (0.8-1). Median volume instilled was $150(140-150) \mathrm{mL}$, with a median recovered volume of $41(27-53) \%$. Tolerance was remarkable since no procedure was interrupted because of discomfort or respiratory failure. Variations in arterial oxygen saturation measured by pulse oximetry were minute, from a median of $-1 \% 10$ min after BAL to $+2 \% 30$ min after. Transient desaturation below $88 \%$ only occurred in two patients without compromising their respiratory status and they rapidly recovered. No other per procedure adverse events were reported. Dyspnoea was evaluated in all but four patients (because of a language barrier). Although it increased immediately after bronchoscopy (from a median (IQR) of 4.2 (2.5-6.8) to 6.1 (4.2-8.9)), dyspnoea returned to baseline level within the first hour post-procedure (4.5 (2.7-6.3); $\mathrm{p}=0.007)$. Operators reported no discomfort linked to the device (median (IQR) score $10(7-10)$ ).

BAL enabled a diagnosis to be reached in 21 patients (70\%), mainly pneumonia in 14 patients, including eight cases of pneumocystis pneumonia. As a result, treatment was modified in $19(63.3 \%)$ patients, either de-escalation $(\mathrm{n}=7,23.3 \%)$, initiation of antimicrobial therapy $(\mathrm{n}=7)$, or initiation of an immunosuppressive therapy $(\mathrm{n}=7)$.

Eight patients required HFNC for more than 4 days of continuous use. A total of six (20\%) patients underwent ETI during their stay, two of them in the first $24 \mathrm{~h}$ (included among the patients mentioned as experiencing failure of the oxygenation strategy), the others underwent ETI after a median (IQR) of 135 (111-222) h post-bronchoscopy, because of worsening of their respiratory disease.

ICU mortality was $16.7 \%$, as four patients died in the ICU within a median (IQR) of 20 (15-25) days after the procedure. All deaths followed withdrawal of life support therapy. Median (IQR) ICU stay was 5 (3-9) days.

Here, we showed that HFNC enabled all BAL procedures to be completed uneventfully. BAL was remarkably well tolerated, with dyspnoea score returning to the baseline value only $1 \mathrm{~h}$ after the procedure. 
Although effectively improving oxygenation [2], NPPV is associated with a number of drawbacks [11]: patient intolerance that may lead to ETI [12]; and difficult access of the bronchoscope to the nares due to the facemask. Only two studies have previously evaluated HFNC during bronchoscopy, both with significant limitations. In a randomised control study, LUCANGelo et al. [7] showed that use of HFNC enabled maintenance of arterial oxygen tension $/ \mathrm{FIO}_{2}$ during the procedure, with significantly better oxygenation with a $60 \mathrm{~L} \cdot \mathrm{min}^{-1}$ flow rate (versus $40 \mathrm{~L} \cdot \mathrm{min}^{-1}$ ). However, their population included non-hypoxaemic patients. A second randomised study compared HFNC to NPPV in hypoxaemic patients requiring bronchoscopy. Although SIMON et al. [8] found that application of NPPV was superior to HFNC with regard to oxygenation before, during and after bronchoscopy, the need for subsequent intubation was similar in the two groups. Moreover, HFNC may have been disadvantaged in their study. First, patients randomised to HFNC were possibly sicker in terms of respiratory failure. Second, bronchoscopy was performed through the mouth, which was maintained open using a bite-block. Hence, positive pressure was substantially reduced $[9,13]$.

In our series, an increase in respiratory support within the first $24 \mathrm{~h}$ was necessary in only $16.7 \%$ of patients (with NPPV for four out of five and ETI for two out of five). This figure compares fairly well with the $25 \%$ reported by CRACCO et al. [14]. In terms of immediate outcome, the increase in respiratory support was not different between HFNC and NPPV in the study by SimON et al. [8] and was in the same range as our study (10\% and $16.7 \%$, respectively). SIMON et al. [8] limited the time frame of HFNC failure to $8 \mathrm{~h}$ after BAL. We were stricter, considering it up to $24 \mathrm{~h}$. With the definition used by SimON et al. [8], our number of failures drops to two. HFNC efficacy can be explained by several mechanisms, as it relieves respiratory distress symptoms and improves oxygenation by washing the dead space, reducing inspiratory nasopharyngeal resistance, and creating a moderate positive airway pressure effect [4].

Despite its prospective and multicentre design, our study has limitations. The limited number of patients is explained by the availability of noninvasive diagnostic strategies [15], but remains similar to other studies $[2,8]$. Our study is not a randomised trial, as our interest was focused on the assessment of HFNC feasibility and safety in view of its potential use outside the ICU. Whereas NPPV is less commonly performed outside the ICU, HFNC is a much simpler device to implement. Further studies are required to evaluate its use outside the ICU and in which patients. NPPV would obviously be too costly and binding for every patient undergoing BAL. HFNC offers the advantage of being easily implemented in all patients.

To conclude, HFNC is a simple, effective, well-tolerated and safe technique to ensure oxygenation during nasal bronchoscopy with BAL in patients with hypoxaemic ARF.

$\circ$

@ERSpublications

HFNC is an effective and safe method of oxygenation during nasal bronchoscopy with BAL in hypoxaemic ARF patients http://ow.ly/XAmtZ

Béatrice La Combe $e^{1,2,3}$, Jonathan Messika ${ }^{1,2,3}$, Vincent Labbé ${ }^{4}$, Keyvan Razazi ${ }^{5}$, Bernard Maitre ${ }^{6}$, Benjamin Sztrymf ${ }^{7}$, Didier Dreyfuss ${ }^{1,2,3}$, Muriel Fartoukh ${ }^{4,8}$ and Jean-Damien Ricard ${ }^{1,2,3}$

${ }^{1}$ AP-HP, Hôpital Louis Mourier, Service de Réanimation Médico-Chirurgicale, Colombes, France. ${ }^{2}$ INSERM, IAME, UMR 1137, Paris, France. ${ }^{3}$ Univ Paris Diderot, IAME, UMR 1137, Sorbonne Paris Cité, Paris, France. ${ }^{4}$ AP-HP, Hôpital Tenon, Service de Réanimation Médico-Chirurgicale, Paris, France. ${ }^{5}$ AP-HP, Hôpital Henri Mondor, Service de Réanimation Médicale, Créteil, France. ${ }^{6}$ AP-HP, Hôpital Henri Mondor, Antenne de Pneumologie, Service de Réanimation Médicale, Créteil, France. ${ }^{7}$ AP-HP, Hôpital Antoine Béclère, Service de Réanimation Médico-Chirurgicale, Clamart, France. ${ }^{8}$ Sorbonne Universités, UPMC Univ Paris 06, Paris, France.

Correspondence: Jean-Damien Ricard, Service de Réanimation Médicale, Hôpital Louis Mourier, 92700 Colombes, France. E-mail: jean-damien.ricard@aphp.fr

Received: Aug 272015 | Accepted after revision: Jan 142016 | First published online: Feb 122016

Clinical trial: This study is registered at clinicaltrials.gov with identifier number NCT02523573.

Conflict of interest: Disclosures can be found alongside the online version of this article at erj.ersjournals.com

Acknowledgements: Jonathan Messika, Muriel Fartoukh and Jean-Damien Ricard are members of the GREPI (French Group for Research and Education in Respiratory Infectious Diseases).

\section{References}

1 Lindholm CE, Ollman B, Snyder J, et al. Flexible fiberoptic bronchoscopy in critical care medicine. Diagnosis, therapy and complications. Crit Care Med 1974; 2: 250-261.

2 Maitre B, Jaber S, Maggiore SM, et al. Continuous positive airway pressure during fiberoptic bronchoscopy in hypoxemic patients. A randomized double-blind study using a new device. Am J Respir Crit Care Med 2000; 162: $1063-1067$.

3 Antonelli $\mathrm{M}$, Conti $\mathrm{G}$, Rocco $\mathrm{M}$, et al. Noninvasive positive-pressure ventilation $v$ s. conventional oxygen supplementation in hypoxemic patients undergoing diagnostic bronchoscopy. Chest 2002; 121: 1149-1154.

4 Ricard J-D. High flow nasal oxygen in acute respiratory failure. Minerva Anestesiol 2012; 78: 836-841. 
5 Sztrymf B, Messika J, Mayot T, et al. Impact of high-flow nasal cannula oxygen therapy on intensive care unit patients with acute respiratory failure: a prospective observational study. J Crit Care 2012; 27: 324.e9-e13.

6 Frat J-P, Thille AW, Mercat A, et al. High-flow oxygen through nasal cannula in acute hypoxemic respiratory failure. N Engl J Med 2015; 372: 2185-2196.

7 Lucangelo U, Vassallo FG, Marras E, et al. High-flow nasal interface improves oxygenation in patients undergoing bronchoscopy. Crit Care Res Pract 2012; 2012: 506382.

8 Simon M, Braune S, Frings D, et al. High-flow nasal cannula oxygen versus non-invasive ventilation in patients with acute hypoxaemic respiratory failure undergoing flexible bronchoscopy - a prospective randomised trial. Crit Care 2014; 18: 712.

9 Parke R, McGuinness S, Eccleston M. Nasal high-flow therapy delivers low level positive airway pressure. $\mathrm{Br} J$ Anaesth 2009; 103: 886-890.

10 Messika J, Ben Ahmed K, Gaudry S, et al. Use of high-flow nasal cannula oxygen therapy in subjects with ARDS: a 1-year observational study. Respir Care 2015; 60: 162-169.

11 Chevrolet JC, Jolliet P, Abajo B, et al. Nasal positive pressure ventilation in patients with acute respiratory failure. Difficult and time-consuming procedure for nurses. Chest 1991; 100: 775-782.

12 Delclaux C, L'Her E, Alberti C, et al. Treatment of acute hypoxemic nonhypercapnic respiratory insufficiency with continuous positive airway pressure delivered by a face mask: a randomized controlled trial. JAMA 2000; 284: $2352-2360$.

13 Groves N, Tobin A. High flow nasal oxygen generates positive airway pressure in adult volunteers. Aust Crit Care 2007; 20: 126-131.

14 Cracco C, Fartoukh M, Prodanovic H, et al. Safety of performing fiberoptic bronchoscopy in critically ill hypoxemic patients with acute respiratory failure. Intensive Care Med 2013; 39: 45-52.

15 Azoulay E, Mokart D, Rabbat A, et al. Diagnostic bronchoscopy in hematology and oncology patients with acute respiratory failure: prospective multicenter data. Crit Care Med 2008; 36: 100-107.

Eur Respir J 2016; 47: 1283-1286 | DOI: 10.1183/13993003.01883-2015 | Copyright (CERS 2016 